\title{
Potencial socioeconômico de produtos florestais não madeireiros na reserva de desenvolvimento sustentável do Uatumã, Amazonas
}

\author{
Socioeconomic potential of non-timber forest products in the sustainable \\ development reserve of Uatumã, Amazonas
}

\author{
Otávio Ferrarim Giatti ${ }^{1}$ (D), Pedro Henrique Mariosa ${ }^{2}$ (ㄷ), Sônia Sena Alfaia ${ }^{3}$ (), \\ Suzy Cristina Pedroza da Silva ${ }^{4}$ (i), Henrique dos Santos Pereira ${ }^{5}$ (i)
}

${ }^{1}$ Instituto Nacional de Pesquisas da Amazônia (INPA), Programa de Pós-graduação em Agricultura no Trópico Úmido (PPGATU), Manaus (AM), Brasil. E-mail: otaviogiatti@gmail.com

${ }^{2}$ Instituto de Natureza e Cultura (INC), Programa de Pós-graduação em Ciências do Ambiente e Sustentabilidade na Amazônia (PPGCASA), Universidade Federal do Amazonas (UFAM), Benjamin Constant (AM), Brasil. E-mail: pedromariosa@ufam.edu.br ${ }^{3}$ Instituto Nacional de Pesquisas da Amazônia (INPA), Manaus (AM), Brasil. E-mail: sonia.alfaia1@gmail.com

${ }^{4}$ Programa de Pós-graduação em Ciências do Ambiente e Sustentabilidade na Amazônia (PPGCASA), Universidade Federal do Amazonas (UFAM), Manaus (AM), Brasil. E-mail: suzyycris@gmail.com

${ }_{5}^{5}$ Programa de Pós-graduação em Ciências do Ambiente e Sustentabilidade na Amazônia (PPGCASA), Faculdade de Ciências Agrárias, Universidade Federal do Amazonas (UFAM), Manaus (AM), Brasil. E-mail: hpereira@ufam.edu.br

Como citar: Giatti, O. F., Mariosa, P. H., Alfaia, S. S., Silva, S. C. P., \& Pereira, H. S. (2021). Potencial socioeconômico de produtos florestais não madeireiros na reserva de desenvolvimento sustentável do Uatumã, Amazonas. Revista de Economia e Sociologia Rural, 59(3), e229510. https://doi.org/10.1590/1806-9479.2021.229510

Resumo: Nas áreas protegidas da Amazônia, o extrativismo de Produtos Florestais Não Madeireiros (PFNMs) é uma das atividades econômicas mais relevantes para o bem-estar das comunidades e para a conservação in situ da agrobiodiversidade. Esta pesquisa objetivou avaliar as atuais práticas de manejo e de comercialização dos PFNMs na Reserva de Desenvolvimento Sustentável do Uatumã, por meio de entrevistas semiestruturadas com 23 unidades familiares e 7 revendedores locais de produtos regionais. Para avaliação do potencial de comercialização, as seguintes variáveis foram consideradas: abundância de PFNMs disponíveis, interesse das famílias, práticas de uso e de manejo, custo de produção, produtividade e rentabilidade. Dos 24 PFNMs coletados pelas famílias, houve maior representatividade nos produtos alimentícios. Com base em 9 indicadores de potencialidade, os 6 PFNMs com maior frequência de comercialização foram avaliados. A oferta e a demanda mostraram-se como variáveis determinantes em todos os PFNMs, e o custo da mão de obra mostrou-se como o fator de maior impacto no custo de produção. Os PFNMs são recursos que contribuem, principalmente, para a segurança alimentar das famílias. É recomendada a intensificação do manejo da copaíba (Copaifera L.), sobretudo para a obtenção de óleo de resina, produto mais bem avaliado pelas unidades familiares e com demanda regional crescente, segundo os revendedores.

Palavras-chave: agrobiodiversidade, áreas protegidas, extrativismo, economia florestal.

\begin{abstract}
In the protected areas of the Amazon, the extraction of Non-Timber Forest Products (NTFPs) is one of the most relevant economic activities for the well-being of communities and for the in situ conservation of agrobiodiversity. This research aimed to evaluate the current management and commercialization practices of NTFPs in the Uatumã Sustainable Development Reserve, through semistructured interviews with 23 family units and 7 local resellers of regional products. We considered the following variables to evaluate the commercialization potential: abundance of available NTFPs, interest of families, use and management practices, cost of production, productivity and profitability. Of the 24 NTFPs collected by the families, there was a greater representativeness in food products. Based on 9 potentiality indicators, we evaluated the 6 NTFPs with the highest frequency of commercialization. Supply and demand proved to be the determining variables in all NTFPs and the cost of labor proved to be the factor with the greatest impact on the cost of production. NTFPs are resources that contribute mainly to household food security. Ours results recommend an intensified management of copaíba (Copaifera L.)
\end{abstract}


mainly for obtaining oil-resin, a product best evaluated by Family Units and with growing regional demand, according to retailers.

Keywords: agrobiodiversity, protected areas, extrativism, forest economy.

\section{INTRODUÇÃO}

Na Floresta Amazônica, a pluriatividade dos agricultores familiares tradicionais resulta do manejo múltiplo da agrobiodiversidade, mediante a combinação de diversas práticas produtivas, como o extrativismo madeireiro e não madeireiro, a caça, a pesca e o cultivo de plantas anuais e perenes. Essas atividades são fundamentais para a reprodução das famílias, pois garantem a obtenção de alimentos e matérias-primas com elevada importância socioeconômica e cultural para essas populações (Carneiro-Filho, 2000; Pereira et al., 2015). Da biodiversidade como um todo, que é a variedade da vida no nível genético das espécies e dos ecossistemas, a agrobiodiversidade é um subconjunto que contribui para a agricultura e a obtenção de alimentos, incluindo plantas e animais em sistema de cultivo, espécies aquáticas e florestais domesticadas e/ou coletadas (Bélanger \& Pilling, 2019). Sendo componentes da agrobiodiversidade, os Produtos Florestais Não Madeireiros (PFNMs) são os materiais biológicos (frutos, óleos, folhas, fibras, raízes e animais silvestres, entre os quais o peixe) extraídos das florestas nativas, com exceção da madeira (De Beer \& McDemott, 1989). Longe de ser uma atividade restrita a determinados locais e de importância apenas no passado, a coleta de PFNMs segue sendo importante econômica e culturalmente em diversos países do mundo (Shackleton \& Pandey, 2014).

A crescente demanda de mercado por PFNMs oferece uma oportunidade de desenvolvimento econômico que pode aliar a inclusão social produtiva de agricultores familiares com a conservação dos ecossistemas florestais (Brites \& Morsello, 2016; Elias \& Santos, 2016; Martinot et al., 2017). Para isso, é fundamental que se compreendam, em determinado contexto socioeconômico, os fatores que influenciam a obtenção e o manejo de diferentes PFNMs, a fim de dinamizar as cadeias de valor daqueles produtos de maior potencial explorados pelas populações locais. Esses fatores estão associados aos locais de coleta, estoque dos produtos, práticas de manejo, interesses das famílias coletoras, usos dos produtos, custo de produção, produtividade, rentabilidade do trabalho e à própria percepção dos coletores sobre a potencialidade de cada um dos produtos manejados. Neste trabalho, serão abordados apenas os produtos de origem vegetal.

O extrativismo é definido na lei que instituiu o Sistema Estadual de Unidades de Conservação, do estado do Amazonas, como sendo um sistema de exploração fundamentado na coleta e extração de recursos naturais (Amazonas, 2007). Na região que hoje corresponde à Amazônia brasileira, o início da exploração de produtos florestais do extrativismo começou no século XVII com a comercialização das chamadas "drogas do sertão", principalmente o cacau, o cravo-do-maranhão, o óleo de copaíba, entre outras. A exploração predatória dos produtos florestais, a guerra e a escravização das populações indígenas continuaram até o século XVIII, quando houve queda da demanda pelo mercado europeu. Apenas por volta de 1890, a navegação a vapor e a internacionalização das águas amazônicas permitiram a reocupação de atividades como a exploração da seringueira (Hevea brasiliensis L.). Esse período vigorou até 1960 , sendo, até essa última década, a principal atividade econômica da Amazônia (Aubertin, 2000). Em 2000, a maioria dos municípios do estado do Amazonas tinha no extrativismo a sua principal atividade comercial (Carneiro-Filho, 2000).

No estado do Amazonas, com o fim do ciclo da borracha e a implantação da Zona Franca de Manaus no final dos anos 1960 (Seráfico \& Seráfico, 2005), houve acelerado crescimento econômico e demográfico da capital do estado (Silva-Araújo, 2017), quando as populações que moravam no interior migraram para aquele centro urbano (Rasse \& Bressolette, 1996). As populações que permaneceram no interior do estado, após terem sido exploradas durante o ciclo da borracha, foram negligenciadas e invisibilizadas pela falta de políticas públicas que as reintegrassem à economia nacional após o colapso da economia gomífera (Aubertin, 2000). A castanha-da-amazônia foi o único produto que continuou a ser explorado e comercializado internacionalmente e que segue até o presente sendo importante para a manutenção do vínculo dessas populações com seus territórios florestais. 
No final dos anos 1980, ameaçados de expulsão de seus territórios tradicionais pela nova política fundiária do governo militar para a Amazônia, os extrativistas se organizaram e pressionaram o governo federal pela garantia de seus direitos à posse da terra (Pinton \& Aubertin, 2000). O movimento Aliança dos Povos da Floresta foi o responsável pela criação do modelo de reforma agrária ecológica para a Amazônia, consolidado da proposta das reservas extrativistas (Barbosa-de-Almeida et al., 2018).

Somente no início dos anos 1990, já com políticas públicas constituídas com o objetivo de garantir os direitos fundiários das populações extrativistas, além de preservar a natureza e agregar valor aos produtos provenientes dela, é que surgiram as primeiras Unidades de Conservação (UCS) na categoria de Reserva Extrativista (RESEX) (Esterci \& Schweickardt, 2010). Com a instituição do Sistema Nacional de Unidades de Conservação (pela Lei Federal no 9.985, de 18 de julho de 2000), sete categorias de UCs de uso sustentável foram estabelecidas, entre as quais as Reservas de Desenvolvimento Sustentável (RDS), que, por serem instrumentos de gestão territorial, podem contribuir para a promoção de atividades sustentáveis (agricultura, criação de animais, manejo florestal, pesca e extrativismo de PFNMs) das populações que nelas habitam (Brasil, 2000; Brasil, 2009; Guimarães, 2013).

Na RDS Uatumã, assim como em outras áreas da região, as atividades produtivas associadas ao manejo dos PFNMs são realizadas em diferentes subcomponentes dos agroecossistemas: capoeira (floresta secundária), mata de terra firme (floresta primária manejada em áreas não alagáveis), sítios (quintais agroflorestais) e igapós (florestas ripárias de rios de água preta) (Shanley \& Medina, 2005; Kummar \& Nair, 2004; Steward et al., 2016). Esses locais divergem em diversos aspectos: localização, espécies que os compõem e abundâncias delas, manejo do local e das espécies, umidade, entrada de luz no ambiente, entre outras características (Lunz \& Franke, 1998; Kummar \& Nair, 2004).

Atualmente, entre os PFNMs da região amazônica como um todo, a castanha-daamazônia (Bertholletia excelsa Bonpl.) é a principal espécie coletada pelas populações tradicionais (Fernandes, 2016; Galeão, 2016). No Amazonas, o tucumã (Astrocaryum tucuma Mart.) possui maior valor entre os PFNMs, destacando-se pelo alto valor agregado desde 0 fim do século passado (Didonet \& Ferraz, 2014; Carneiro-Filho, 2000). A resina da copaíba e o óleo de andiroba (Carapa guianensis Aubl.) são as principais matérias-primas para produção de fitoterápicos, além de serem comercializados em óleos de modo informal no mercado local, regional e nacional (Carvalho, 2015; Santos, 2016). As raízes de cipós e a resina de breu (Protium Burm.f.; Burseraceae) são importantes produtos manufatureiros para consumo e comercialização (Plowden, 2001). A resina de breu possui múltiplas funções, como iniciador de fogo, incenso, produtos medicinais e material de calafetagem de barco de madeira (Plowden, 2001). Os cipós, como materiais flexíveis e resistentes, são empregados nas construções e na confecção de artesanatos (Plowden, 2003).

Se, por um lado, a atividade extrativista é considerada como insuficiente para proporcionar autonomia financeira em médio e longo prazo às populações tradicionais (Homma, 2014), por outro não há dúvida de que a atividade é importante fornecedora de alimentos da culinária local e de compostos para a medicina tradicional, além de propiciar a obtenção de matérias-primas para a construção de moradias e de objetos e ferramentas de grande utilidade, especialmente ligados aos modos de vida tradicionais. Os PFNMs têm servido como importantes componentes da renda familiar e, em muitos casos, podendo ser a única fonte de renda e único acesso a bens de consumo (Carneiro-Filho, 2000; Lescure, 2000). Assim, o extrativismo vegetal é a atividade econômica que, somada à agricultura, pesca e caça, compõe o sistema produtivo polivalente das famílias tradicionais (Pinton \& Aubertin, 2000; Pereira et al., 2015). No entanto, a ênfase excessiva dos projetos de desenvolvimento da economia extrativa na mercantilização dos PFNMs desviou a atenção dos meios de subsistência locais, do acesso a recursos e das questões de subsistência (Shanley et al., 2002). A excessiva atenção aos mercados globais em detrimento aos locais vem resultando em menor valorização de seu papel no apoio aos meios de subsistência e em uma maior marginalização dos grupos de baixa renda envolvidos (Shackleton et al., 2007).

Para corrigir essas distorções e efetivamente incentivar o fortalecimento das cadeias de valor dos PFNMs de modo que resultem em melhoria socioeconômica das comunidades tradicionais, é necessário que as unidades de produção familiar tenham: interesse em 
trabalhar com o produto; detenham conhecimento cultural sobre o uso e beneficiamento dessas espécies; disponham de mão de obra e tecnologia de coleta e beneficiamento; que na unidade familiar (UF) exista abundância suficiente do produto; que exista mercado para esse produto e que este apresente demanda (Figura 1) (Carrazza et al., 2012; Homma, 2015; Neves et al., 2016; Galeão, 2016).

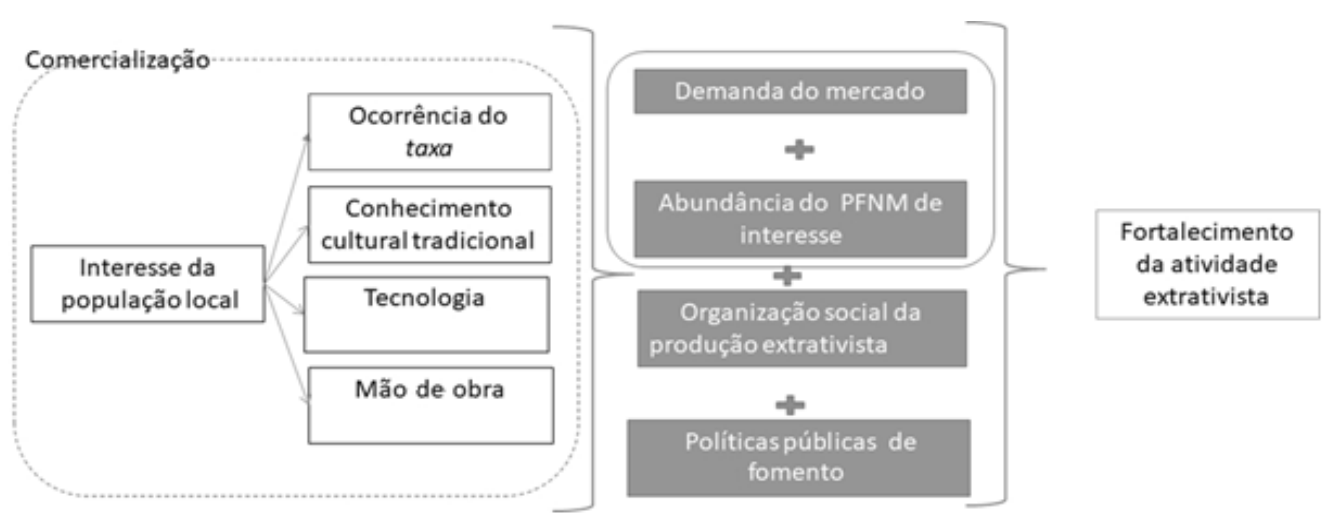

Figura 1 Síntese do modelo teórico para formação do potencial das atividades extrativistas.

Mais especificamente na RDS Uatumã, locus desta pesquisa, o Plano de Gestão (PG) revisado em 2017 (Secretaria Estadual do Meio Ambiente, 2017) registrou a demanda por estudos que possibilitassem a otimização da produção e o manejo adequado para melhor aproveitamento dos PFNMs. A coleta de PFNMs é um trabalho árduo, mas também é um ato de resistência, de defesa da floresta e de um modo de vida. Muitos castanheiros se consideram "ricos" por causa da fartura de alimentos, de biodiversidade e da floresta em pé. Para os povos indígenas, a safra da castanha também representa fazer vigilância do seu território, transmitir os conhecimentos tradicionais e valores de extrema relevância para essas populações e para a consolidação da base territorial extrativista (Fernandes, 2016).

Houve, de fato, a ampliação das áreas protegidas para manutenção das florestas extrativas protegidas (Soares-Filho et al., 2010) e manejadas pelas comunidades tradicionais, e essas áreas ainda mantêm uma grande diversidade de subcomponentes em agroecossistemas ricos em PFNMs. Entretanto, ações de políticas públicas que propiciem a inclusão produtiva dessas populações e que contemplem a diversidade cultural e étnica dos povos e comunidades tradicionais ainda são insuficientes (Carrazza et al., 2012; Shackleton \& Pandey 2014; Secretaria Estadual do Meio Ambiente, 2017).

Neste sentido, considerando-se a necessidade da consolidação das RDS como categoria de UC e instrumento de gestão pública, que visa à preservação ambiental e à melhoria na qualidade de vida das populações moradoras, esta presente pesquisa oferece bases teóricometodológicas para avaliação do potencial das atividades de exploração de PFNMs para o desenvolvimento local. Para tanto, foram avaliadas as atuais práticas de manejo e comercialização dos PFNMs na perspectiva das UFs de produção da RDS Uatumã. A partir desse diagnóstico, foi avaliado o potencial socioeconômico dos principais PFNMs mediante indicadores objetivos e dados empíricos de campo e indicadores subjetivos com base na percepção das UFs de produção.

\section{METODOLOGIA}

Neste trabalho, os extrativistas foram considerados como um segmento do que se convencionou denominar por "povos e comunidades tradicionais", os quais, de acordo com a Política Nacional de Desenvolvimento de Povos e Comunidades Tradicionais (Brasil, 2007), são definidos como grupos culturalmente diferenciados, autoidentificados, com formas próprias de organização social, utilizando territórios e recursos como base para sua reprodução cultural, social, religiosa, ancestral e econômica. Os produtores extrativistas aqui serão referidos como UFs ou simplesmente famílias. 
Participaram desta pesquisa de 3 a 10 UFs por produto e 7 revendedores que compraram os produtos das famílias entrevistadas. Revendedor aqui se refere ao agente de comercialização intermediário operador do processo de compra, logística e venda dos insumos produzidos pelas UFs. Em muitos casos, nas comunidades distantes das capitais, pode assumir denominação também de atravessador, patrão, patrãozinho ou regatão (Menezes, 2012), o que varia de acordo com a natureza da relação entre o agente social intermediário e o produtor/extrativista. Entre as informações colhidas dos agentes da comercialização estão: destino da comercialização, preço de revenda e quantidade comercializada.

Esta pesquisa foi autorizada pelo Comitê de Ética em Pesquisa com Seres Humanos do Instituto Nacional de Pesquisa da Amazônia, sob CAAE 96583618.2.0000.0006, e pela Secretaria do Estado do Meio Ambiente do Amazonas (SEMA) e Departamento de Mudanças Climáticas e Gestão de Unidades de Conservação (DEMUC), sob n 136/2017. Possuiu ainda anuência da Associação de Moradores da RDS do Uatumã e das lideranças das comunidades trabalhadas.

O estudo foi realizado na RDS do Uatumã, criada em 2004 a partir da assinatura do Decreto Estadual $n^{\circ}$ 24.295, de 25 de junho de 2004. A RDS possui 424.425 ha, localizada a $200 \mathrm{~km}$ ao nordeste da cidade de Manaus, em linha reta, entre as coordenadas 59॰ $10^{`} 58,4^{`}$ Sul e $2^{\circ} 27^{`} 2,4^{`}$ Oeste (Figura 2). A gestão de áreas protegidas estaduais, como a RDS do Uatumã, está sob a coordenação da Secretaria de Estado e do Meio Ambiente (SEMA), por meio do Departamento de Mudanças Climáticas e Gestão de Unidades de Conservação (DEMUC). A SEMA, por meio do DEMUC, preside o Conselho Gestor da RDS.

Desde a época de sua implantação, a população da RDS do Uatumã está espacialmente organizada em 20 comunidades. Em 2007, as comunidades eram compostas de 257 famílias, variando de 4 a 28 famílias por comunidade, totalizando 1.312 pessoas (Instituto de Conservação e Desenvolvimento Sustentável da Amazônia, 2009). Em 2016, com a revisão do PG, foram contabilizadas 361 famílias, com total de 1.644 pessoas (Secretaria Estadual do Meio Ambiente, 2017), o que representa uma elevada taxa de crescimento na ordem de $2,6 \%$ ao ano.

Os moradores da RDS são representados pela Associação Agroextrativista das Comunidades da Reserva de Desenvolvimento Sustentável do Uatumã (AACRDSU). As famílias associadas arcam com mensalidades de $\mathrm{R} \$$ 9,54 (1\% do salário mínimo - ano-base 2018) e são, especialmente, extrativistas, agricultores e pescadores, que utilizam os produtos dessas atividades primeiramente para uso próprio. A farinha de mandioca, o pescado e a caça formam a base alimentar dessas famílias. Além disso, a farinha é responsável pela principal renda econômica para 66\% das famílias e está presente em todas as comunidades (Secretaria Estadual do Meio Ambiente, 2017). Realizam pluriatividades ao longo do ano, como pesca comercial, caça, extrativismo, trabalho assalariado e trabalho com turismo de pesca esportiva, sendo que algumas dessas atividades são periódicas (Instituto de Conservação e Desenvolvimento Sustentável da Amazônia, 2009; Guimarães, 2013; Secretaria Estadual do Meio Ambiente, 2017).

Além da coleta nas áreas de uso intensivo, com o extrativismo de produtos como a castanha-da-amazônia, cuja coleta ocorre durante o período de dezembro a maio, época de queda dos frutos, as famílias utilizam áreas consideradas particulares ou comunitárias localizadas na zona de uso extensivo da RDS. Conforme o zoneamento da RDS, as zonas de uso extensivo são áreas florestais, que juntas somam 162.338,45 ha, o equivalente a 41,55\% da área total. Nessas áreas, são permitidos aos comunitários a prática do extrativismo madeireiro para consumo próprio em explorações de pequena escala e o extrativismo não madeireiro para consumo e comercialização (Secretaria Estadual do Meio Ambiente, 2017).

A coleta de dados ocorreu em 2018, durante os períodos de 11 de janeiro a 10 de fevereiro; de 5 a 20 de março; de 13 a 24 de abril; e de 19 a 26 de junho. Os dados foram obtidos mediante entrevistas semiestruturadas com 23 UFs de 6 comunidades que trabalhavam com PFNMs. As comunidades Maracarana $(n=5)$, Santa Luzia do Caranatuba $(n=1)$, São Francisco do Caribi $(n=5)$, Nossa Senhora do Livramento $(n=5)$, Santa Luzia do Jacarequara $(n=4)$ e Bom Jesus $(n=3)$ (Figura 1$)$ foram selecionadas a partir de indicações fornecidas pela presidente da associação dos moradores, pelo gestor da RDS, pelo IDESAM 
(ONG, antiga cogestora da RDS, que, atualmente, desenvolve projetos na RDS) e também por moradores da RDS do Uatumã.

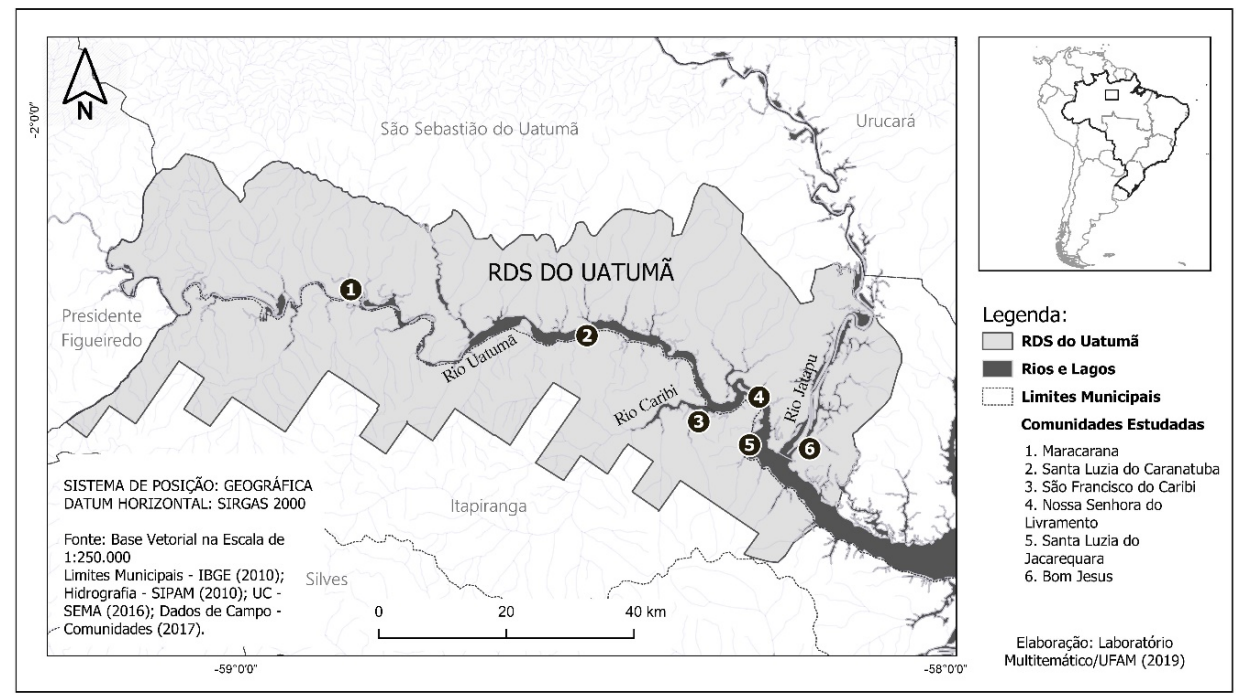

Figura 2 Localização da RDS do Uatumã, Amazonas.

As UFs nucleares (Lacombe, 1984; Sakamoto et al., 2016) foram consideradas como as unidades amostrais da pesquisa e são aquelas cujos membros da família habitam e trabalham em uma mesma unidade ou nas quais há ajuda mútua de outras UFs de mesmo parentesco que habitam outra unidade, como pais e irmãos, visto que essas comunidades rurais representam grandes famílias matriarcadas e/ou patriarcadas.

As entrevistas semiestruturadas com uso de formulário foram conduzidas durante visitas guiadas às áreas de coleta. Para a inclusão das UFs na pesquisa, foi utilizado o método bola de neve (Bayle, 1994), em que a indicação dos entrevistados foi obtida em entrevistas iniciais com as lideranças de cada comunidade. Na ocasião, foi pedido aos líderes que indicassem as famílias que trabalhavam com maior frequência na coleta de PFNMs. A seguir, a cada nova entrevista, o participante recomendava, entre as UFs constantes da lista, uma próxima a ser entrevistada.

Do mesmo modo, a partir de entrevistas semiestruturadas, foi realizado um levantamento sobre os processos produtivos, as cadeias de valores e os custos de produção de seis PFNMs. Esses produtos foram escolhidos por possuírem três ou mais UFs que os comercializam, sendo: fruto de tucumã, semente da castanha-da-amazônia, óleo de andiroba, óleo de copaíba, resina de breu e artesanatos de cipós, feitos de raízes de cipó-titica (Heteropsis flexuosa (Kunth) G.S.Bunting), cipó-ambé (Philodendron Schott) e cipó-açu (Evodianthus funifer (Poit.) Lindm.). Cabe ressaltar que o custo total aqui foi considerado como o custo de produção, ou seja, a soma dos custos variáveis e fixos, enquanto o custo com a mão de obra foi referente a um dos custos variáveis e dizia respeito à soma dos dias trabalhados (diária) pelos produtores de cada família. Sendo assim, foram levados em consideração, nos seis principais PFNMs, os destinos primários da produção, canais de comercialização, comunidades principais, preços pagos pelos PFNMs e preço remuneratório estimado com a internalização da remuneração de diárias trabalhadas no preço do produto. Para a análise de rentabilidade, foi tomado como referência o valor praticado no local para a remuneração de diárias pelo trabalho de coleta de PFNMs.

A análise de custo dos produtos castanha-da-amazônia e óleo de andiroba foi relativo à produção de 2018, visto que foi possível analisar toda a safra desse ano e calcular a produção no final dela. Para a resina de breu e raízes de cipós, produtos que geralmente eram comercializados por encomendas, foram analisados dados referentes a 2017 e 2018. Já para 
o óleo de copaíba e o fruto de tucumã, que possuíam comercialização durante todo o ano, foi analisada a produção de 2017.

Para avaliar a percepção das UFs quanto aos pontos fortes e fracos da cadeia de valor de cada produto, foram utilizados nove indicadores subjetivos: preço comercializado, demanda de comercialização, tempo gasto com a atividade, distância da área de coleta, abundância do produto, sazonalidade do produto, perecibilidade do produto, exigência do trabalho e regime de posse (comunitária ou particular), avaliados a partir da categorização posterior, por análise de conteúdo das respostas obtidas em entrevistas abertas e classificadas em um gradiente de 3 pontos - ruim (1), médio (2) e bom (3) -, com exceção do regime de posse, que foi avaliado em uma escala de dois níveis - médio (2), quando a área está em áreas comunitárias, e bom (3), quando em áreas particulares.

Para avaliar objetivamente o potencial econômico de cada um dos produtos, foram utilizados indicadores de produção por UF investigada, sendo estes: número de produtores; soma de dias trabalhados; custo total de produção; quantidade comercializada; produtividade; custo por unidade do produto comercializado; renda bruta da UF; renda líquida da UF; renda líquida do produtor da UF; remuneração média por produtor da UF por dia. As unidades consideradas para cada produto foram: a semente da castanha-da-amazônia em latas de 18 litros; o fruto do tucumã em sacos de $50 \mathrm{~kg}$; a andiroba e a copaíba em litros; a resina do breu em quilos; e as raízes do cipós em unidade ou beneficiadas em artesanatos.

\section{RESULTADOS E DISCUSSÃO}

As normas locais para o manejo extrativista na RDS do Uatumã foram definidas em dois momentos: de uma maneira geral, pelas regras apresentadas no PG da UC, quando diretrizes gerais foram determinadas em oficinas comunitárias participativas e consultas públicas; e, posteriormente, de modo detalhado, pelo documento de Boas Práticas de Manejo Extrativista da RDS do Uatumã, que detalhou as práticas extrativistas de manejo e conservação (Instituto de Conservação e Desenvolvimento Sustentável da Amazônia, 2009; Instituto de Conservação e Desenvolvimento Sustentável da Amazônia, 2013).

No mapeamento participativo elaborado para a primeira versão do PG em 2008, a respeito das áreas extrativas, foram identificados 42 PFNMs de origem vegetal de conhecimento de suas 20 comunidades (Instituto de Conservação e Desenvolvimento Sustentável da Amazônia, 2009). Com base em estudos realizados na RDS no período de 2008 a 2011, Guimarães (2013) levantou um total de 17 espécies de produção extrativista comercializadas pelos moradores da RDS, indicando que 59\% dos produtos eram comercializados por menos de $20 \%$ das famílias que manejavam as espécies. De acordo com o autor, a comercialização era realizada de forma individual aos mercados locais, não havendo organização coletiva para a comercialização da produção agrícola/extrativista.

\section{Local de Coleta, Unidades Familiares e Usos do PFNMs}

Nesta pesquisa, foi identificada a utilização de 24 taxa (grupos taxonômicos), dos quais eram coletados os PFNMs, o que se aproximou da quantidade de 26 PFNMs levantados na revisão do PG em 2016 (Secretaria Estadual do Meio Ambiente, 2017). Os taxa são manejados em quatro subcomponentes do agroecossistema (floresta manejada, sítio, capoeira e igapó). Por causa do tamanho reduzido de sítios e capoeiras, não foi possível diferenciá-los no mapeamento participativo, e ambos foram demarcados como sítios.

Entre os 19 taxa citados no ambiente de floresta manejada, 16 ocorriam exclusivamente nesse ambiente. As espécies de castanheiras, andirobeiras, bacabeiras e açaizeiros foram relatadas em florestas manejadas, sítios e capoeiras. Como esperado, o tucumã foi encontrado apenas em sítios e capoeiras, enquanto as espécies presentes nos igapós não ocorreram em outros subcomponentes do agroecossistema. A espécie mari-mari (Cassia leiandra Benth.) foi relatada em apenas uma entrevista, em razão da pouca disponibilidade do fruto. Por outro lado, de acordo com relatos, há uma abundância de arbustos de camucamu (Myrciaria dubia H. B. K. (McVaugh)) ao longo de toda a margem do rio Uatumã, entre a comunidade Caranatuba até a proximidade da sede do município de Itapiranga. Segundo os 
entrevistados, era estimada uma produção de pelo menos 15 mil frutos por safra. No entanto, no PG, não houve inventário sobre o potencial desse produto (Tabela 1).

Tabela 1 Lista de taxa dos quais foram obtidos PFNMs nas unidades familiares estudadas e os diferentes subcomponentes do agroecossistema de ocorrência.

\section{Floresta manejada (19)}

Açaí; andiroba; amapá; bacaba; castanha-da-amazônia; breu;

buriti; cipó-ambé; cipó-titica; cipóaçu; copaíba; cumaru; palha

(Arecaceae Schultz Sch.); patauá; pau-rosa (Aniba rosaeodora

Ducke); piquiá; saracura-mirá; uxicoroa; uxi-liso
Sítio (5) Capoeira (4) Igapó (3)
Açaí; andiroba; bacaba; castanha-daamazônia; tucumã
Açaí; bacaba; castanha-daamazônia; tucumã
Camu-camu; jauari (Astrocaryum jauari Mart.); mari-mari

Foram levantados 11 produtos com fins alimentícios, 8 manufatureiros e 5 medicinais, sendo estes últimos a copaíba, a andiroba, o cumaru (Dipteryx odorata (Aubl.) Willd.), o amapá (Brosimum potabile Ducke) e a saracura-mirá (Ampelozizyphus amazonicus Ducke). A castanhada-amazônia foi o PFNM coletado pelo maior número de UFs, 17 ao todo, distribuídas entre as 6 comunidades estudadas, confirmando os resultados obtidos por Guimarães (2013) em estudo realizado na RDS. A castanha-da-amazônia é consumida na forma in natura ou triturada em concentrado aquoso ("leite"), com ingrediente da "tapioca" (preparado de amido de mandioca) ou de doces. O produto foi comercializado por 10 UFs.

Foram contabilizados 9 PFNMs coletados exclusivamente para consumo próprio, enquanto outros 15 foram comercializados. Entre os produtos exclusivos para o consumo alimentício, destacaram-se os frutos de bacaba (Oenocarpus distichus Mart.), piquiá (Caryocar villosum (Aubl.) Pers.), uxi-coroa (Duckesia verrucosa (Ducke) Cuatrec.), uxi-liso (Endopleura uchi (Huber) Cuatrec.), buruti e patauá (Oenocarpus bataua Mart.). A polpa extraída dos frutos de palmeiras, como bacaba, patauá, açaí (Euterpe precatoria Mart.) e buriti (Mauritia flexuosa L.f.), era consumida em diluição em água ou "vinhos", como normalmente os produtores denominavam. Como aponta Soares et al. (2018), o extrativismo proporciona alimentos diversificados, contribuindo para a manutenção desses agricultores na área rural, principalmente pelo fato de reduzir a insegurança alimentar em razão da disponibilidade básica de alimentos nutricionalmente ricos (Yuyama et al., 2007).

Dos 15 PFNMs comercializados na RDS do Uatumã, destacaram-se pelo menos 6 com oportunidade de potencial econômico (castanha-da-amazônia, frutos de tucumã, resina de breu, óleo de copaíba, óleo de andiroba e artesanatos de cipós) comercializados por três ou mais UFs. A mão de obra das etapas do processo produtivo era composta da própria UF nuclear.

\section{Descrição do Processo de Comercialização e Análise de Custo}

\section{1) Castanha-da-amazônia}

Na RDS do Uatumã, a comercialização da castanha-da-amazônia era feita por meio de cinco canais de comercialização, sendo que $40 \%$ dos produtores acessavam mais de um tipo de revendedor (Tabela 2). Em 2018, a comunidade Bom Jesus foi uma das que mais coletou castanha-da-amazônia. A discrepância na quantidade de latas de castanhas comercializadas entre os produtores pode estar associada não apenas à diferença na produtividade dos castanhais, mas à competição entre os coletores. Famílias que reivindicavam o acesso exclusivo às áreas de coleta podiam acumular maior volume de produto do que aquelas que compartilhavam uma mesma área. 
Tabela 2 Número de famílias por faixas de rentabilidade líquida diária estimada por trabalhador.

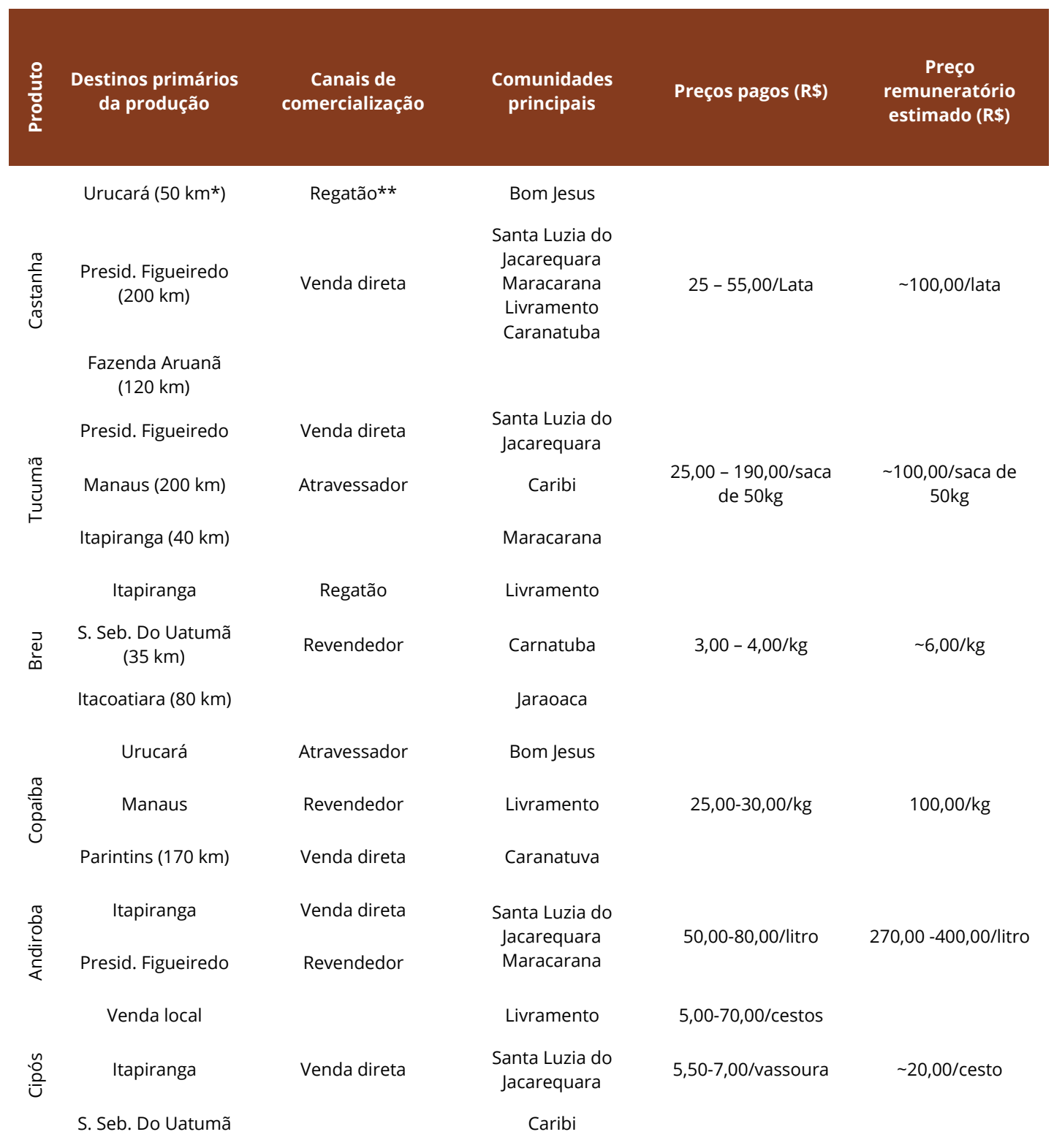

* Distância em quilômetros aproximada em linha reta. A distância em linha reta é apenas para fins de comparação, uma vez que, no Amazonas, as distâncias são muito maiores, uma vez que o transporte majoritariamente hidroviário acompanha a sinuosidade dos rios. **Atravessador - compra do produtor para vender ao consumidor final; Revendedor - compra do produtor para fazer estoque e revender para a indústria ou para o comércio varejista. Regatão - comerciante ambulante embarcado que realiza escambo.

Os preços pagos pelos compradores possuíam tendência a diminuir no decorrer da safra, resultado do aumento da oferta de castanha no mercado. Para Fernandes (2016), no município de Manicoré, no Amazonas, a lata de castanha-da-amazônia era comercializada para revendedores por $\mathrm{R} \$ 45,00$, enquanto o preço da castanha com casca pago pela Política de Garantia do Preço Mínimo (PGPM) equivalia a $R \$ 1,27 / \mathrm{kg}$, sendo que em uma lata havia aproximadamente 10 quilos de castanha (Fernandes, 2016; Tonini et al., 2017). Portanto, o preço ofertado pelo programa mostrava-se o menor para o mercado da castanha. Quanto à PGPM-Bio, foi analisado que nenhuma das 23 famílias entrevistadas acessava a política, pois a desconheciam; apenas uma família sabia de sua existência. No entanto, estavam incluídas na PGPM-Bio apenas a castanha-da-amazônia e as sementes de andiroba.

Apenas uma entre as sete UFs teve os dias de trabalhos remunerados pelo valor superior a $\mathrm{R} \$ 50,00$, valor da diária local. Neves et al. (2016) afirmam que a disponibilidade do recurso influencia a viabilidade econômica da castanha, corroborando os resultados encontrados por 
Araújo, Soares \& Wadt (2017), que demonstraram o retorno econômico superior a $R \$ 50,00$ aos indígenas de Rio Branco que possuíam castanhais próprios e abundantes. Em um cenário hipotético em que os produtores teriam cada dia de trabalho remunerado em $R \$ 50,00^{1}$, o preço da lata da castanha deveria ser o dobro do atualmente praticado (Tabela 2).

\section{2) Tucumã}

Não havia beneficiamento do tucumã na RDS do Uatumã; os frutos coletados permaneciam nos sacos até a comercialização, e, em razão de sua alta perecibilidade, não podia haver atrasos. O transporte era realizado por embarcação própria e/ou por embarcação da prefeitura com três destinos possíveis (Tabela 2). Existiam duas reivindicações dos extrativistas: a primeira era o transporte para a cidade duas vezes ao mês durante a safra por conta da alta perecibilidade; a segunda era o fornecimento de energia elétrica, que permitiria beneficiar os frutos e conservar a "polpa de tucumã". O beneficiamento poderia agregar valor ao produto, como acontecia em Manaus (Didonet \& Ferraz, 2014).

Os maiores valores pagos às unidades familiares ocorreram no início da safra (fevereiro) e também na entressafra (de junho a agosto) (Tabela 2). De acordo com Didonet \& Ferraz (2014), em Manaus essa lógica é inversa, pois, no mês de agosto (maior oferta de tucumã), os preços caem. Entre os destinos de comercialização, os feirantes de Presidente Figueiredo foram os melhores pagantes no início da safra, com o preço chegando a $R \$ 190,00$, provavelmente por causa da menor oferta de tucumã na região e da maior demanda proporcional, ao comparar com a alta oferta de tucumãs em Manaus e a baixa demanda dos aproximados 9 mil habitantes de Itapiranga (Instituto Brasileiro de Geografia e Estatistica, 2018).

O valor pago aos produtores pelo revendedor variava de acordo com o preço do saco comercializado em Manaus. O valor da saca duplicava na entressafra em Manaus, e o nível de exigência dos compradores diminuía. A venda para Manaus apresentava um alto custo de produção quando comparado aos outros destinos. Esse alto custo estava relacionado, principalmente, aos custos variáveis que compunham o custo total, com maior peso em quatro atividades: pré-coleta, combustível para se deslocar da reserva até Itapiranga, frete dos sacos e passagem do produtor até Manaus, que somadas equivaliam a 92,41\% do custo total.

Para as UFs que transportavam o produto até Manaus, os valores recebidos deveriam ser superior a $\mathrm{R} \$ 100,00$ por unidade (no caso, saca de $50 \mathrm{~kg}$ ) (Tabela 2). Para as demais, esse valor já seria suficiente para assegurar uma renda mínima.

\section{3) Вreu}

Esse produto tradicional foi comercializado em 2018 com um regatão no porto da comunidade, que percorria a região somente durante a safra da castanha-da-amazônia. Como não houve produção de castanha em 2017, o regatão não entrou na RDS para comercializar outros produtos. Para os outros destinos da produção (Tabela 2), o produto era transportado em próprias embarcações das UFs. Em Itapiranga, o produto era comercializado com um revendedor local que revendia o produto em Manaus. As UFs comercializaram o breu com seis compradores durante os anos de 2017 e 2018 (Tabela 2).

Os valores recebidos pelas famílias não variaram amplamente como foi observado em outros produtos (Tabela 2). Um dos revendedores afirmou comprar aproximadamente mil quilos de breu por ano e ter preferência na compra do produto solto, pois possibilitava acessar mercados além das lojas de construção. Na capital amazonense, o revendedor afirmava que a variação de preço ocorria em razão da oscilação de oferta nas lojas voltadas a construções. Como as coletas da resina de breu eram realizadas por meio de encomendas, as quantias e os preços comercializados eram preestabelecidos. Como o preço do quilo do breu variava pouco, a produtividade era determinante para variação da remuneração entre as UFs. A única das UFs a comercializar em 2018, apesar de não ter custos com

\footnotetext{
1 Valor autodeclarado pago em média para uma diária de serviço prestado no processo de obtenção de um PFNM.
} 
beneficiamento e comercialização, não obteve lucro, principalmente pela baixa produtividade e alta emprego de mão de obra. A produtividade dessa UF provavelmente também tenha sido afetada pela área de coleta, que, segundo os moradores, possuía menor abundância de breu, quando comparada às áreas mais distantes, como as de Jaraoaca. Quando questionados sobre qual seria o preço justo do breu, os valores informados pelas famílias variaram de $\mathrm{R} \$ 5,00$ a $\mathrm{R} \$ 8,00$ por quilo, valor que corresponde ao valor estimado neste estudo (Tabela 2).

\section{4) Copaíba}

As famílias comercializavam o óleo de copaíba apenas em dois mercados locais e um regional (Tabela 2), corroborando os resultados de Santos (2016), que indicaram que a maioria da produção do estado do Amazonas tinha como destino a região centro-sul do país, onde o produto entrava na cadeia de produção dos mercados de cosméticos e medicamentos. O preço pago pelos revendedores aos produtores (Tabela 2) era acima do valor registrado em outras localidades produtoras. Em Lábrea, por exemplo, o povoado Jammandi, com a APOAN, comercializou o óleo a R $\$ 12,00$ por litro (Santos, 2016). Os revendedores declararam renegociar o óleo por $\mathrm{R} \$ 35,00$ a outros revendedores de Manaus e Parintins. O preço de revenda dos comerciantes corroborou os preços encontrados por Silva et al. (2018) em Santarém, no Pará, onde o litro do óleo era comercializado de $R \$ 40,00$ a $\mathrm{R} \$ 50,00$ por feirantes do mercado municipal.

Nenhuma das UFs analisadas tiveram seus dias de trabalhos remunerados pelo valor superior a $R \$ 50,00$, equivalente à diária local. O preço comercializado era um dos fatores determinantes para o insucesso da atividade. Os custos elevados para produção de um litro de óleo e a menor produtividade resultaram em uma remuneração inferior a $R \$ 15,00$ por dia trabalhado. A produtividade das famílias poderia estar sendo influenciada pela abundância de copaibeiras nas áreas de coleta. As áreas de coleta do Livramento e do Bom Jesus possuíam mais copaibeiras que as áreas exploradas pela família de Caranatuba. Esse fato levou a UF de Caranatuba a acampar em áreas mais afastadas para coletar o óleo, além de buscar outros produtos extrativos, tais como o camu-camu.

A média do preço considerado justo estimado para as UFs era maior do que o dobro do preço pago pelos revendedores. Como a exploração de copaíba era uma atividade recente (máximo três anos) para os entrevistados, as áreas exploradas eram delimitadas pelas comunidades, com isso a produção de copaíba poderia decair nos próximos anos em razão de o estoque do produto ser limitado (Homma, 2015), como já acontece em algumas das áreas exploradas.

O principal questionamento das famílias em relação à comercialização do óleo foi justamente o baixo preço praticado, o que, segundo eles, deveria ser algo em torno de $R \$ 35,00$ a $R \$ 40,00$, para ser justo. Seria necessário elevar o preço pago aos produtores para diminuir o nível de intensidade de exploração do recurso, a fim de manter o manejo sustentável. Para isso, seria preciso, além de inserir o produto na política de preços mínimos, rever o método utilizado pela PGPM-Bio para fixar o preço dos produtos, visto que, atualmente, ela determina o preço mínimo referente ao custo de produção dos produtos.

\section{5) Andiroba}

A produção artesanal do óleo de andiroba variou de 1,4 a 5 litros entre as famílias por safra. Essas famílias afirmaram que a demanda do óleo de andiroba era maior do que a produção, o que ajudava a explicar a maior valorização do produto em relação aos demais (Tabela 2). Apesar disso, o óleo era comercializado em um menor número de comunidades e de destinos da produção.

A análise de custo do processo do óleo foi realizada apenas com duas UFs. Como as andirobeiras estavam nos quintais, não havia gasto variável com gasolina e custos fixos de depreciação de motores e barcos, resultando no custo total menor que $R \$ 3,00$ para ambas as famílias. Apesar do baixo custo com variáveis de produção, as UFs não obtiveram a remuneração da mão de obra igual ou superior a $\mathrm{R} \$ 50,00$ por causa da baixa produção, em relação aos diversos dias utilizados para produção do óleo. 
No Médio Juruá, onde o beneficiamento do óleo ocorre de modo industrial, os valores variaram de $\mathrm{R} \$ 39,01$ dia/pessoa a $\mathrm{R} \$ 17,75 \mathrm{dia} /$ pessoa em estudo realizado por Instituto de Conservação e Desenvolvimento Sustentável da Amazônia (2013). Carvalho (2015), ao comparar o preço dos produtos da semente de andiroba no mercado em diferentes níveis de processamento, encontrou que a lata de 18 quilos de semente custava $R \$ 10,00$, e o óleo, $\mathrm{R} \$ 22,00 / \mathrm{kg}$. Já o preço mínimo pago pela PGPM era de $\mathrm{R} \$ 1,60 / \mathrm{kg}$ da semente. A PGPM não fazia subvenção em relação à produção do óleo, o que poderia ser corrigido.

Por ser um produto processado e com um longo tempo de fabricação, requer um maior emprego de mão de obra, além da baixa produtividade do processo artesanal. Assim, para que os produtores conseguissem remunerar a mão de obra em $\mathrm{R} \$ 50,00$ por dia trabalhado, o valor comercializado deveria ser de 6 a 8 vezes maior que o atualmente praticado.

\section{6) Cipós}

Os cipós eram comercializados, sobretudo, já beneficiados artesanalmente na forma de cestos, vassouras e outros pequenos objetos. Havia produtores que comercializavam apenas quando havia encomendas, e os destinos de comercialização eram as lojas situadas em cidades mais próximas, além dos próprios moradores da RDS (Tabela 2).

Os preços variavam para cada tipo e tamanho de objeto (Tabela 2). As vassouras chegavam a ser revendidas pelo preço de $R \$ 10,00$ nas lojas das cidades. Esses números corroboram os resultados de Santos et al. (2018), que encontrou um aumento médio de $30 \%$ a $70 \%$ do preço em produtos de cipó-titica comprados de produtores da FLONA do Tapajós por revendedores de Santarém, no Pará.

O cálculo do custo de produção teve como base a experiência de uma família da comunidade de Santa Luzia do Jacarequara, que comercializou 60 cestarias por mês, em média. O custo sobre a mão de obra foi o principal responsável pelo ressarcimento menor que $R \$ 50,00$. Durante o beneficiamento, as duas artesãs da família utilizam 20 dias para confeccionar as 60 cestarias. Portanto, o tempo gasto durante o processo produtivo culminado com o baixo preço de comercialização resultou em uma remuneração abaixo do desejável. Para que essas famílias fossem remuneradas em $\mathrm{R} \$ 50,00$ por dia trabalhado, as cestarias teriam que ser vendidas a $\mathrm{R} \$ 37,41$, quase o dobro do valor comercializado.

\section{Comparando os PFNMs - Processo Produtivo x Cadeia de Valor}

A dinâmica de oferta e demanda do mercado local era influenciada pelas condições de comercialização dos principais produtos coletados na RDS. Para a castanha e o tucumã, o fator mais importante foi a variação dos preços ao longo da safra. Na comercialização do breu e dos cipós, feitos sob encomendas, merece destaque o papel dos revendedores locais, que exerciam o papel de controle como gerentes dessas duas cadeias de expressão local. Já as cadeias da copaíba e da andiroba, segundo os revendedores, possuíam a possibilidade de expansão de mercado regional e nacional, que poderiam oferecer maior rentabilidade a toda a cadeia.

$\mathrm{Se}$, por um lado, quanto maior o valor pago pelo produto, maior é a possibilidade que o resultado seja distribuído por toda a cadeia, por outro, como afirmam Alexiades \& Shanley (2004), se essa distribuição não acontece, são agravadas as diferenças socioeconômicas entre o extrativista e o revendedor. No caso do óleo de copaíba, a produção era considerada como de alto potencial pelo fato de haver a possibilidade de extração contínua durante todo o ano, apresentar alta demanda do mercado e ser um produto não perecível. Apesar desses fatores, houve o declínio na produção do óleo nos últimos anos, como pode ser verificado nas entrevistas com três famílias na RDS, notadamente pela não acessibilidade a mercados compradores.

Em relação à castanha, a disponibilidade de acesso aos castanhais, sua produtividade (produção de ouriços por árvore) e a queda nos preços, principalmente em razão do aumento da oferta no mercado, foram determinantes para o retorno econômico. Os castanhais apresentaram uma grande variação de produtividade interanual, havendo a ocorrência de anos sem produção, ou seja, sem safra (Wadt et al., 2005). No outro extremo, há o caso do tucumã, para o qual, nas últimas safras, ocorreu uma maior produção, e isso impactou na logística de escoamento, fazendo com que muitos frutos não fossem aproveitados. 


\section{Rentabilidade dos PFNMs}

A remuneração por dia trabalhado quase sempre não ultrapassou o valor da diária local, que era de $R \$ 50,00$. Os fatores que influenciaram a baixa remuneração dessas famílias foram determinados essencialmente por: 1) tipo de produto, 2) preço de venda e 3) custos de mão de obra com a coleta.

Entre os PFNMs analisados (castanha, tucumã, breu, copaíba e andiroba), o breu apresentou melhor rentabilidade para mais de uma família, com média diária acima de $R \$ 50,00$, seguido pelo tucumã (entre $R \$ 40,00$ e $R \$ 50,00$ ) e a castanha, com renda média diária de $R \$ 10,00$. Com média calculada para uma UF apenas, é possível destacar a copaíba, com renda acima de $R \$ 50,00$, e a andiroba, com valores entre $R \$ 10,00$ a $R \$ 30,00$ da renda líquida por dia trabalhado. O potencial socioeconômico do breu, da castanha e da copaíba é determinado, principalmente, pela ocorrência e disponibilidade do recurso nas florestas extrativas, o que influencia a sua produtividade e, consequentemente determina os seus custos de produção. Para a produção artesanal do óleo de andiroba, foi observada uma produção relativamente pequena diante dos dias de trabalho (Figura 3). A rentabilidade dos cipós não foi estimada por causa da insuficiência dos dados, pois a estimativa da remuneração por dia trabalhado foi calculada com precisão para uma única família e somente para a coleta de uma das espécies, no caso, o cipó-ambé.

\section{Potencial dos Produtos - Indicadores de Tomadas de Decisão}

O óleo de copaíba foi o produto comercializado mais bem avaliado pelos entrevistados. Em todos indicadores, o produto obteve média acima de dois pontos (Figura 4). Quando as três UFs coletoras de copaíba foram questionadas sobre a preferência por esse PFNM, todas afirmaram que os motivos para sua escolha se deviam à sua produção contínua e alta demanda do mercado. $O$ baixo número de UFs que trabalhavam com a copaíba pode estar relacionado a dois fatores de ordem cultural: o não conhecimento de práticas modernas de coleta da copaíba, que evitam o abate das árvores para a extração do óleo de resina, e a falta de experiência com a espécie e o seu produto, já que 13 UFs entrevistadas alegaram nunca ter trabalhado com o produto.

O breu, segundo produto mais bem avaliado, também apresentou os indicadores com média acima de dois. Porém, o indicador "demanda de comercialização" foi avaliado como "bom" por três famílias. A demanda pelo produto se concentrou em Itacoatiara, enquanto nas cidades mais próximas da RDS existiam poucos compradores ou nenhum. $\mathrm{O}$ acesso a esse mercado comprador, por ser mais distante, era menos acessível aos produtores, tendo sido citado por apenas uma família, a qual comercializou o breu em Itacoatiara nos dois últimos anos (2017 e 2018). A falta de compradores foi a principal justificativa das famílias que não trabalhavam com esse produto (Figura 4). A unidade familiar do Livramento, que comercializou o breu em 2018 com o regatão, afirmou que, se houvesse "comprador certo", preferia trabalhar com o breu do que com a castanha. As famílias de Maracarana afirmaram não trabalhar com breu por não existir demanda em Presidente Figueiredo. Já as famílias das outras comunidades alegaram a falta de demanda pelo produto e o fato de nunca terem trabalhado com breu como os principais motivos para não optarem por ele.

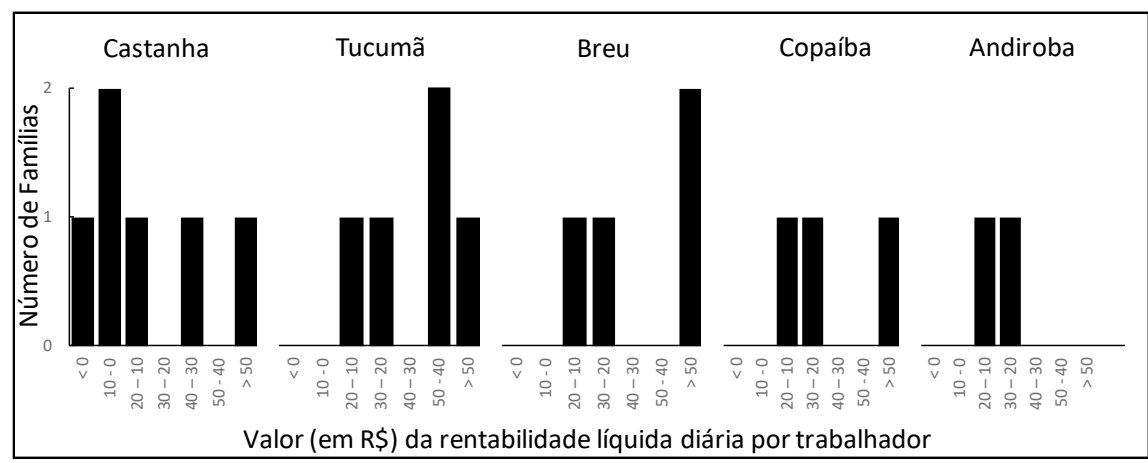

Figura 3 Número de famílias por faixas de rentabilidade líquida diária estimada por trabalhador. 
O fruto do tucumã, apesar de ter sido avaliado como de alto preço, apresentou demanda avaliada em valores inferiores ao nível médio (Figura 4), em razão de duas famílias de Maracarana e uma família do Livramento apontarem não haver demanda para comprar tucumã dentro da RDS, no porto das comunidades. Outros indicadores importantes para o tucumã foram: a alta perecibilidade do fruto, que resultou em perda da maioria da produção; e a dificuldade de se trabalhar com a espécie, por causa do seu estirpe liso e próximo ao ápice do pedúnculo, densamente espinhosa. As famílias que não trabalhavam com o fruto de tucumã alegaram, principalmente, não ter a espécie em suas propriedades, ainda que ela ocorresse exclusivamente em sítios e em capoeiras.

Os entrevistados avaliaram o trabalho com artesanatos de cipós como difícil e demorado. Além disso, julgaram o preço e a demanda como médios (Figura 4). Apesar dessas avaliações, metade dos entrevistados alegou gostar de trabalhar com cipó, pois apreciavam tecer e realizavam o trabalho em casa: "Eu gosto de tecer e posso trabalhar aqui em casa, sentada na sombra e cuidando das crianças e das outras coisas" (Entrevista realizada com família de Santa Luzia do Jacarequara em 29 de janeiro de 2018), o que indica para um valor sociocultural para além do monetário. A maioria das famílias que não trabalhavam com os cipós alegou não saber confeccionar os artesanatos. Das que sabiam, muitas deixaram de trabalhar nesses últimos dois anos em razão da falta de compradores.

O óleo de andiroba foi avaliado por duas unidades como produto de abundância média por causa da quantidade de sementes produzidas nos sítios dessas UFs, e não pela quantidade de óleo produzido (Figura 4). O potencial desse produto foi influenciado positivamente pela distância, demanda e preço comercializado, e negativamente pela sazonalidade e tempo do processo produtivo.

A castanha-da-amazônia, produto com maior número de UFs produtoras, apesar de ter apresentado alta demanda, teve o preço considerado próximo ao valor médio (Figura 4). Além disso, a produção dos ouriços apresentou sazonalidade que impedia as famílias de trabalhar o ano inteiro com o produto. Provavelmente, o alto número de famílias que coletaram a castanha-da-amazônia, quando comparado aos demais produtos, está relacionado com diferentes processos, como o aprendizado adquirido com os familiares, a alta demanda e a necessidade de pouco investimento para a coleta, processamento, armazenamento e comercialização. Com exceção de uma UF do Livramento, que afirmou não coletar castanha pela pouca disponibilidade do recurso nas áreas da comunidade, os demais alegaram não trabalhar com esse produto por não ter acesso a castanhais.

A mão de obra familiar participou de todas as operações da atividade florestal não madeireira, pois, geralmente, essas operações estavam relacionadas à geração de renda ou segurança alimentar, como é o caso do açaí e do buriti, para citar dois importantes PFNMs alimentícios da região (Ribeiro et al., 2004). Apesar da disponibilidade de produção e mão de obra, a remuneração por dia trabalhado pelas UFs da RDS poucas vezes atingiu o valor da diária local de $R \$ 50,00$. Assim, torna-se necessário apoiar essas cadeias extrativistas, a partir da organização social e do apoio do conselho deliberativo, associação de moradores e prefeituras, para realização de um planejamento estratégico das atividades e efetivamente desenvolver o potencial dos PFNMs na RDS. Essas cadeias poderiam ser motivadas a partir capacitação e a definição de novas estratégias para estimular a participação da população local, como a descentralização do local de realização das reuniões e a necessidade de apoio para locomoção dos representantes da sociedade civil (Olival et al., 2007).

É possível desenvolver a Amazônia a partir das dinâmicas locais de produção que não degradam os recursos naturais em quantidades similares aos grandes empreendimentos e, mesmo assim, gerar emprego e renda para parte expressiva da população agrária (Herrera et al., 2014). Isso significa permitir que produtores familiares sejam sujeitos do desenvolvimento com incentivos que considerem suas especificidades locais.

As cadeias de produção e consumo dos PFNMs possuem uma gama numerosa e heterogênea de atores que ocupam diferentes espaços geográficos e socioeconômicos muito diferentes. Quanto mais extensa a cadeia, maiores são as diferenças socioeconômicas entre os extrativistas e aqueles que comercializam os produtos finais (Alexiades \& Shanley, 2004).

Foi constatado que, no nível da economia familiar, os moradores da RDS do Uatumã asseguravam uma renda líquida suficiente a partir da coleta dos PFNMs. Isso corrobora a 
observação feita por Barbosa-de-Almeida et al. (2018) sobre a não extinção do extrativismo em nível microeconômico, uma vez que a importância em nível local dos produtos alimentícios e medicinais e a possibilidade de articulação com mercados regionais e nacional se apresentam como possibilidade ainda vigente.
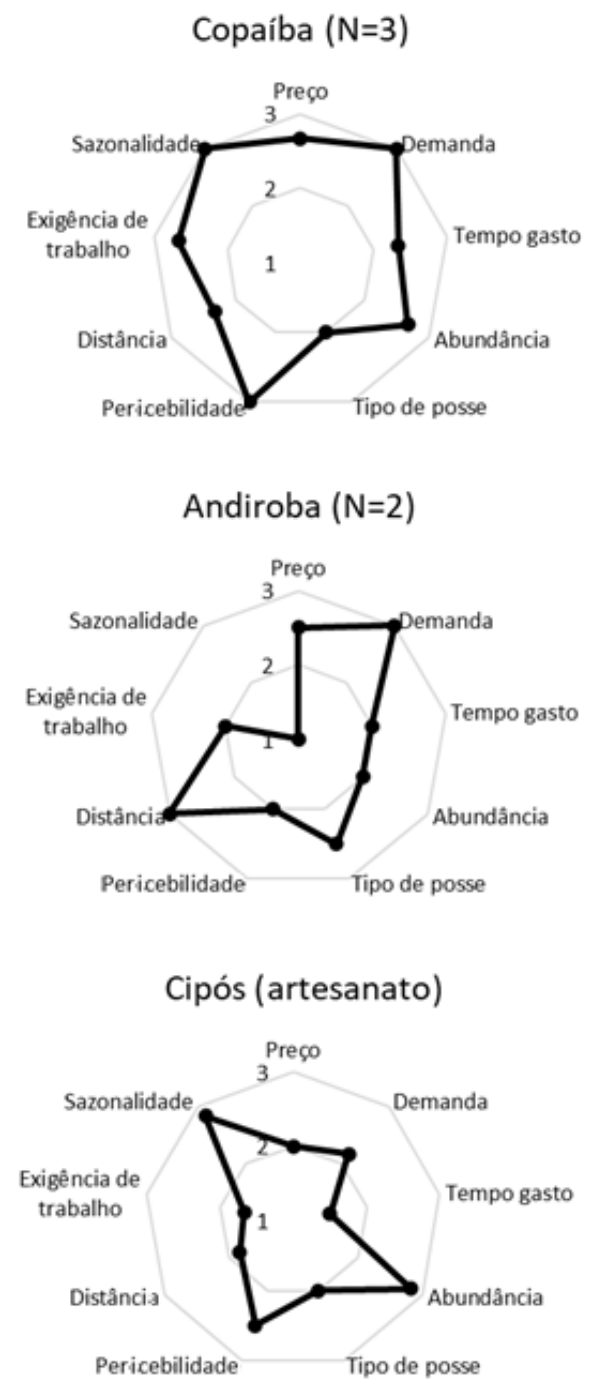

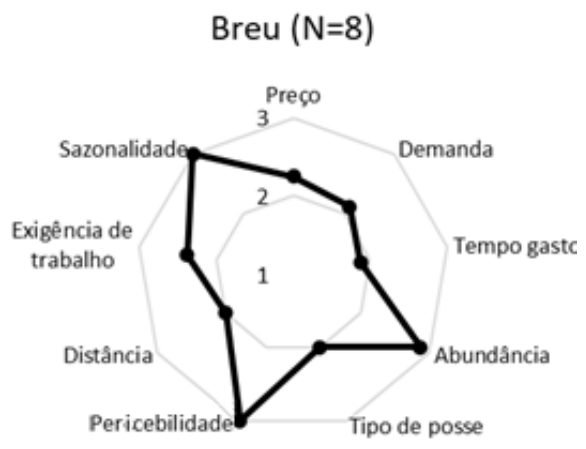

Castanha $(\mathrm{N}=9)$

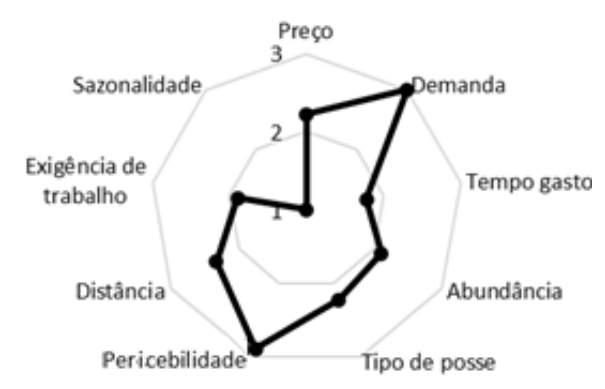

Tucumã ( $\mathrm{N}=5$ )

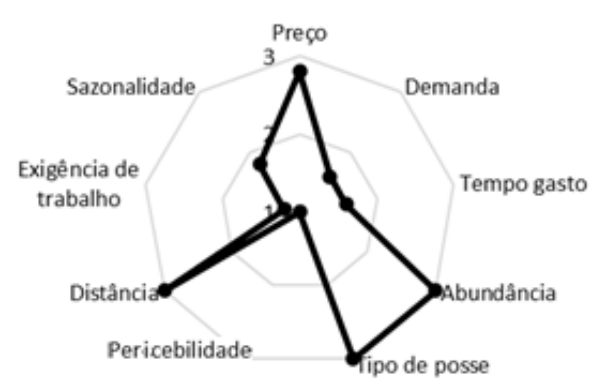

Figura 4 Avaliação dos indicadores de percepção (1 = ruim, 2 = médio e 3 = bom) das unidades familiares sobre os PFNMs.

\section{CONCLUSÕES}

Na RDS do Uatumã, as famílias manejavam simultaneamente quatro subcomponentes dos agroecossistemas (floresta manejada, igapó, sítio e capoeira), sendo as florestas manejadas os locais com as maiores coocorrências entre os produtos. Ainda, coletavam nesses locais pelo menos 25 PFNMs.

No que tange aos produtos utilizados para alimentação e comercialização, é possível destacar a castanha-da-amazônia como o mais representativo em termos de volume comercializado e do número de famílias envolvidas.

Entre os PFNMs potenciais explorados em menor frequência entre as UFs, o açaí, o camucamu, o breu, o tucumã e a copaíba carecem de estudos específicos, a partir do mapeamento de suas cadeias de valor para estimular seus mercados locais e regionais. $O$ breu foi o produto que apresentou melhor rentabilidade para as famílias, no entanto possuía uma baixa demanda local. O tucumã, embora abundante na região, tinha sérias restrições quanto à 
logística, o que implicou elevadas perdas durante seu escoamento. A coleta de cipós exigia melhores condições de manejo e agregação de valor.

Dos produtos atualmente comercializados, no curto prazo, o óleo de copaíba apresentou os melhores indicadores socioeconômicos, pois tinha um mercado regional com demanda crescente, uma produção que não sofria com a sazonalidade e era um produto de baixa perecibilidade. No entanto, a falta de conhecimento de boas práticas de manejo e de manipulação foi um fator decisivo que impedia sua larga exploração na RDS. Já o breu apresentou um maior potencial em médio a longo prazo, já que foi o produto que melhor remunerou as famílias e foi o segundo produto mais bem avaliado, apesar de não ter alta demanda, o que pode ser superado com ações que visem conectar a cadeia local com centros consumidores.

Outro fator importante nesse tipo de economia foi a garantia do preço mínimo praticado dentro da RDS, o que poderia incentivar a continuidade da coleta e, principalmente, torná-la efetivamente rentável e, por conseguinte, sustentável. Essa meta poderia ser alcançada pela inclusão de todos os PFNMs elencados neste estudo na Política de Garantia de Preços Mínimos da Sociobiodiversidade (PGPM-Bio), considerando como referência para a remuneração justa o valor da diária de trabalho despendida pelos extrativistas no manejo e beneficiamento dos PFNMs. O pagamento do preço mínimo poderia assegurar uma renda líquida suficiente para manter o engajamento das famílias coletoras nas atividades produtivas e na conservação dos recursos florestais.

\section{REFERÊNCIAS BIBLIOGRÁFICAS}

Alexiades, M. N., \& Shanley, P. (2004). Productos forestales, medios de subsistencia y conservacion: estudios de caso sobre sistemas de manejo de produtos forestales no maderables (Vol. 3, 516 p.). Indonesia: CIFOR.

Amazonas. (2007, junho 05). Lei Complementar n 53/2007, de 05 de junho de 2007. Regulamenta o inciso V do artigo 230 e o § 1.? do artigo 231 da Constituição Estadual, institui o Sistema Estadual de Unidades de Conservação - SEUC, dispondo sobre infrações e penalidades e estabelecendo outras providências. Diário Oficial Assembleia Legislativa do Estado do Amazonas. Manaus, AM.

Araújo, L. V., Soares, J. G., \& Wadt, L. H. O. (2017). Custo de extração da castanha-da-Amazônia na terra indígena Rio Branco - RO (Comunicado Técnico, n. 408, 5 p.). Porto Velho: Embrapa.

Aubertin, C. (2000). A ocupação da Amazônia: Das drogas do sertão à biodiversidade. In L. Emperaire (Ed.), A floresta em jogo. O extrativismo na Amazônia central (pp. 151-160). São Paulo: UNESP.

Barbosa-de-Almeida, M. W., Allegretti, M. H., \& Postigo, A. (2018). O legado de Chico Mendes: êxitos e entraves das Reservas Extrativistas. Desenvolvimento e Meio Ambiente, UFPR, 48, 25-55.

Bayle, K. (1994). Methods of social social reserarch (4th ed., 588 p.). New York: The Free Pass.

Bélanger, J., \& Pilling, D. (2019). The State of the World's Biodiversity for Food and Agriculture (572 p.). Rome, Italy: Food and Agriculture Assessments. Recuperado em 23 de julho de 2020, de http://www.fao.org/3/CA3129EN/CA3129EN.pdf

Brasil. (2000, junho 18). Lei nº 9.985, de 18 de julho de 2000. Regulamenta o art. 225, § 1o, incisos I, II, III e VII da Constituição Federal, institui o Sistema Nacional de Unidades de Conservação da Natureza e dá outras providências. Diário Oficial [da] República Federativa do Brasil, Brasília.

Brasil. (2007, fevereiro 7). Decreto $n^{\circ}$ 6.040, de 7 de fevereiro de 2007. Institui a Política Nacional de Desenvolvimento Sustentável dos Povos e Comunidades Tradicionais. Diário Oficial [da] República Federativa do Brasil, Brasília.

Brasil. (2009). Plano nacional de promoção das cadeias de produtos da sociobiodiversidade (21 p.). Brasília, DF: Ministério do Desenvolvimento Agrário.

Brites, A. D., \& Morsello, C. (2016). Efeitos ecológicos da exploração de produtos florestais não madeireiros: uma revisão sistemática. Desenvolvimento e Meio Ambiente, 36(4), 55-72.

Carneiro-Filho, A. (2000). Os principais produtos extrativistas e suas áreas de produção. In L. Emperaire (Ed.), A floresta em jogo. O extrativismo na Amazônia central (pp. 91-98). São Paulo: UNESP.

Carrazza, L. R., Noleto, R.A. \& Filizola, B. C. (2012). Cadernos de Normas Fiscais, Sanitárias e Ambientais para regularização de agroindústrias comunitárias de produtos de uso sustentável da biodiversidade ( 2 . ed.) Brasília-DF: ISPN. 
Carvalho, T. P. V. (2015). Mercado de fitoterápicos e fitocosméticos em Manaus (AM) (Dissertação de mestrado). Universidade Federal do Amazonas, Manaus, Amazonas. 190 p.

De Beer, J. H., \& McDemott, M. (1989). The economic value of non-timber forest products in South East Asia. Amsterdam: The Netherlands Committee for IUCN.

Didonet, A. A., \& Ferraz, I. D. K. (2014). O comércio de frutos de tucumã (Astrocaryum aculeatum g. Mey arecaceae) nas feiras de Manaus (Amazonas, Brasil). Revista Brasileira de Fruticultura, 36(2), 353-362.

Elias, G. A., \& Santos, R. (2016). Produtos florestais não madeireiros e valor potencial de exploração sustentável da floresta atlântica no sul de Santa Catarina. Ciência Florestal, 26(1), 249-262.

Esterci, N., \& Schweickardt, K.H.S.C. (2010). Territórios amazônicos de reforma agrária e de conservação da natureza. Boletim do Museu Paraense Emilio Goeldi de Ciências Humanas, 5(1), 59-77.

Fernandes, F. (2016). Potencialidades e limites da cadeia de valor da Castanha do brasil (bertholletia excelsa) no município de Manicoré, Sul do Amazonas (29 p.). Brasília: Instituto Internacional de Educação do Brasil.

Galeão, P. (2016). Potencialidades e limites da cadeia de valor da castanha do Brasil em Boca do Acre (20 p.). Brasília: Instituto Internacional de Educação do Brasil.

Guimarães, E. R. (2013). Caracterização e diagnóstico do uso da terra na Reserva de Desenvolvimento Sustentável de Uatumã, AM (Dissertação de mestrado). Instituto Nacional de Pesquisa da Amazônia, Manaus, Amazônia. 110 p.

Herrera, J. A., Ramos, P., \& Silva, J. U. B. D. (2014). Novas estratégias produtivas na Amazônia: estudo sobre os produtores agropecuários familiares no sudoeste paraense. Revista de Economia e Sociologia Rural, 52, 223-242.

Homma, A. K. O. (2014). Cemitério das castanheiras. In A. K. O. Homma (Ed.), Extrativismo vegetal na Amazônia: história, ecologia, economia e domesticação. Brasília: Embrapa.

Homma, A. K. O. (2015). Em favor de uma nova agricultura na Amazônia. Terceira Margem: Amazônia. 1(5), 59-74.

Instituto Brasileiro de Geografia e Estatistica - IBGE. (2018). População no último censo de Itapiranga, Amazonas. Recuperado em 23 de julho de 2020, de https://cidades.ibge.gov.br/brasil/am/itapiranga/panorama acesso em 05/09/2018

Instituto de Conservação e Desenvolvimento Sustentável da Amazônia - IDESAM. (2009). Plano de Gestão da Reserva de Desenvolvimento Sustentável do Uatumã (RDS) (338р.). Manaus, AM: IDESAM.

Instituto de Conservação e Desenvolvimento Sustentável da Amazônia - IDESAM. (2013). Manual de Boas Práticas Extrativistas da RDS do Uatumã (60 p.). Manaus, AM: IDESAM.

Kummar, B. M. \& Nair, P. K. R. (2004). The enigma of tropical homegardens. Agroforestry Systems, 61, 135-152.

Lacombe, P. (1984). La pluriactivité et l'évolution des exploitations agricoles. In Association Des Ruralistes Français. La pluriactivité dans les familles agricoles. (pp. 35-53). Paris: ARF.

Lescure, J. P. (2000). Algumas questões a respeito do extrativismo. In L. Emperaire (Ed.), A floresta em jogo. O extrativismo na Amazônia central (pp. 191-204). São Paulo: UNESP

Lunz, A. M. P., \& Franke, I. L. (1998). Princípios gerais e planejamento de sistemas agroflorestais (27 p.). Rio Branco: Embrapa-CPAF/AC.

Martinot, J. F., Pereira, H. D. S., \& Silva, S. C. P. D. (2017). Coletar ou Cultivar: As escolhas dos produtores de açaí-da-mata (Euterpe precatoria) do Amazonas. Revista de Economia e Sociologia Rural, 55(4), 751 766.

Menezes, E. S. (2012). Os "piaçabeiros" no médio rio Negro: identidades coletivas e conflitos territoriais. (Dissertação). Programa de Pós-graduação em Antropologia Social, Universidade Federal do Amazonas, Manaus.

Neves. E.S, Wadt, L.H.O. \& Guedes. M.C. (2016). Estrutura populacional e potencial para o manejo de Bertholletia excelsa (Bonpl.) em castanhais nativos do Acre e Amapá. Scientia. Forestalis, 44(109), 1931.

Olival, A. D. A., Spexoto, A. A., \& Rodrigues, J. A. (2007). Participação e cultura política: os conselhos municipais de desenvolvimento rural sustentável no território Portal da Amazônia. Revista de Economia e Sociologia Rural, 45(4), 1013-1035.

Pereira, H. S., Vinhote, M. L. A., Zingra, A. F. C., \& Takeda, W. M. (2015). A multifuncionalidade da agricultura familiar no Amazonas: desafios para a inovação sustentável (Vol. 1, No. 5, pp. 59-74). Amazonia: Terceira Margem. 
Pinton, F., \& Aubertin, C. (2000). Extrativismo e desenvolvimento regional. In: Emperaire, L (Ed). A floresta em jogo. O extrativismo na Amazônia central (pp. 151-160). São Paulo: UNESP.

Plowden, J. C. (2001). The ecology, management and marketing of non-timber forest products in the alto rio guamá indigenous reserve (eastern brazilian amazon) (Master's thesis). The Pennsylvania State University, Pennsylvania.

Plowden, J. C. (2003). Production ecology of copaíba (Copaifera spp) oleoresin in the Eastern Brazilian Amazon. Economic Botany, 57, 491-501.

Rasse, E., \& Bressolette, V. (1996). Devenir de l'extractivisme en périphérie de Manaus. La Foret En Jeu: L'Extractivisme En Amazonie Centrale (73 p.). Nederlands: IRD Editions.

Ribeiro, R. N. D. S., Santana, A. C. D., \& Tourinho, M. M. (2004). Análise exploratória da socioeconomia de sistemas agroflorestais em várzea flúvio-marinha, Cametá-Pará, Brasil. Revista de Economia e Sociologia Rural, 42(1346-2016-105089), 133-152.

Sakamoto, C. L., Nascimento, C. A., \& Maia, A. G. (2016). As famílias pluriativas e não agrícolas no rural brasileiro: condicionantes e diferenciais de renda. Revista de Economia e Sociologia Rural, 54(3), 561 582.

Santos, A. D. (2016). Potencialidade e limites da cadeia de valor dos óleos de essências florestais no sul do Amazonas (15 p). Brasília: Instituto Internacional de Educação do Brasil.

Santos, L. E., Gama, J. R. V., Ribeiro, R. B. S., Silva, A. A., Cruz, G. S., \& Rodrigue, B. L. (2018). Inventário de cipó titica na Floresta Nacional do Tapajós e comercialização em Santarém, Pará. Advances in Forestry Science, 5(2), 309-314.

Secretaria Estadual do Meio Ambiente - SEMA. (2017). Revisão do plano de gestão da Reserva de Desenvolvimento Sustentável do Uatumã (115 p.). Itapiranga, São Sebastião do Uatumã: SEMA.

Seráfico, J., \& Seráfico, M. (2005). A Zona Franca de Manaus e o capitalismo no Brasil. Estudos Avançados, 19(54), 99-113.

Shackleton, C. M., \& Pandey, A. K. (2014). Positioning non-timber forest products on the development agenda. Forest Policy and Economics, 38, 1-7.

Shackleton, S., Shanley, P., \& Ndoye, O. (2007). Invisible but viable: Recognising local markets for nontimber forest products. International Forestry Review, 9(3), 697-712.

Shanley, P., \& Medina, G. (2005). Frutíferas e plantas úteis na vida Amazônica (300p.). Belém: CIFOR, Imazon.

Shanley, P., Luz, L., \& Swingland, I. R. (2002). The faint promise of a distant market: a survey of Belém's trade in non-timber forest products. Biodiversity and Conservation, 11, 615-636.

Silva, A. A., Santos, L. E., Cruz, G. S., Ribeiro, R. B. S., \& Gama, J. R. V. (2018). Potencial de comercialização de Produtos Florestais Não Madeireiros na área de manejo da Reserva Extrativista Tapajós Arapiuns. Acta Tecnológica., 13(1), 45-63.

Silva-Araújo, E. (2017). Desenvolvimento urbano local: o caso da Zona Franca de Manaus. Urbe. Revista Brasileira de Gestão Urbana, 1(1), 33-42.

Soares, K. R., Ferreira, E. E. D. S., Seabra-Junior, S., \& Neves, S. M. A. D. S. (2018). Extrativismo e produção de alimentos como estratégia de reprodução de agricultores familiares do assentamento Seringal, Amazônia Meridional. Revista de Economia e Sociologia Rural, 56(4), 645-662.

Soares-Filho, B., Moutinho, P., Nepstad, D., Anderson, A., Rodrigues, H., Garcia, R., Dietzsch, L., Merry, F., Bowman, M., Hissa, L., Silvestrini, R., \& Maretti, C. (2010). Role of Brazilian Amazon protected areas in climate change mitigation. Proceedings of the National Academy of Sciences of the United States of America, 107(24), 10821-10826.

Steward, A. M., Rognante, C., \& Brito, S. V. (2016). Roça sem fogo: a visão de agricultores e técnicos sobre uma experiência de manejo na reserva de desenvolvimento sustentável Amanã, Amazonas, Brasil. Biodiversidade Brasileira, 6(2), 71-87.

Tonini, H., Baldoni, A. B., Hoogerheide, E. S. S., \& Botelho, S. C. C. (2017). Caracterização e rentabilidade do sistema extrativista da castanha-do-brasil praticado em Itaúba (MT). Nativa (Sinop), 5(3), 175 181.

Wadt, L. H. O., Kainer, A. K., \& Gomes-Silva, D. A. P. (2005). Population structure and nut yield of a Bertholletia excelsa stand in Southwestern Amazonia. Elsevier Forest Ecology and Management, 211, 371-384.

Yuyama, L. K. O., Aguiar, J. P.L., Pantoja, L., Maeda, R. N., Melo, T., Alencar, F. H., Nascimento, A. M. M., Negreiros, N. M. A., Corrêa, A. M. S., \& Pérez-Escamilla, R. (2007). Segurança/insegurança alimentar 
em famílias urbanas e rurais no estado do Amazonas: I. Validação de metodologia de instrumento de coleta de informação. Acta Amazonica, 37(2), 247-252.

Submetido: 2/out/2019

Aceito: $2 / \mathrm{nov} / 2020$

Classificação JEL: N56 - Latin America ; Caribbean 